\title{
Understandings on the Inhibition of Oxygen Reduction Reaction by Bromide Adsorption on Pt(111) Electrodes at Different pH Values
}

\author{
Valentín Briega-Martos, Gisele A. B. Mello, ${ }^{\text {a }}$ Rosa M. Arán-Ais, ${ }^{\text {b,c }}$ Víctor Climent, \\ Enrique Herrero, ${ }^{*}$ and Juan M. Feliu (1)*,z
}

Instituto de Electroquímica, Universidad de Alicante, E-03080 Alicante, Spain

Oxygen reduction reaction (ORR) is studied on $\mathrm{Pt}(111)$ in the presence of different concentrations of bromide anions at different $\mathrm{pH}$ values ranging from very acidic to neutral solutions. While adsorbed bromide inhibits the ORR, the strength of the inhibition decreases when the $\mathrm{pH}$ is increased. This is a consequence of the lower relative adsorption energy of bromide at higher $\mathrm{pH}$ values, caused by the lower absolute applied potential. This is reflected in a shift of the onset of the ORR (as measured with the hanging meniscus rotating disc electrode, HMRDE) to higher values as the $\mathrm{pH}$ is increased. HMRDE measurements reveal that the limiting current density $\left(j_{\text {lim }}\right)$ coincides with the theoretical value for two electrons only at very acidic solutions. However, when pH is increased, $j_{\text {lim }}$ tends toward the value for a four electrons reaction. From $\mathrm{pH}>3 \mathrm{j}_{\text {lim }}$ coincides both in the presence and in the absence of bromide despite the specific anion adsorption. Experiments in solutions with different ionic strength and hydrogen peroxide reduction measurements suggest that the formation of a reaction intermediate different from $\mathrm{H}_{2} \mathrm{O}_{2}$ is favored at neutral $\mathrm{pH}$ values. (C) The Author(s) 2018. Published by ECS. This is an open access article distributed under the terms of the Creative Commons Attribution Non-Commercial No Derivatives 4.0 License (CC BY-NC-ND, http://creativecommons.org/licenses/by-nc-nd/4.0/), which permits non-commercial reuse, distribution, and reproduction in any medium, provided the original work is not changed in any way and is properly cited. For permission for commercial reuse, please email: oa@electrochem.org. [DOI: 10.1149/2.0081815jes]

(cc) BY-NC-ND

Manuscript submitted July 30, 2018; revised manuscript received August 28, 2018. Published September 7, 2018. This paper is part of the JES Focus Issue on Electrocatalysis - In Honor of Radoslav Adzic.

The full understanding of the oxygen reduction reaction (ORR) is mandatory in order to achieve valuable knowledge for energy conversion technologies such as fuel cells and lithium-air batteries. Although many experimental and theoretical studies carried out during the last years have contributed to significant improvements in the understanding of this complex reaction, its detailed mechanism has not been completely elucidated yet. ${ }^{1}$ This reaction mechanism must be complex, since it involves several electron and proton transfer steps $(4$ electrons and 4 protons are exchanged in the complete reduction of $\mathrm{O}_{2}$ to water). This implies the formation of several intermediates such as adsorbed $\mathrm{OH}, \mathrm{O}$ and $\mathrm{OOH}$. Among these, the hydroperoxyl radical $\left(\mathrm{OOH}^{\bullet}\right)$ has been proposed in several previous works as an intermediate in acidic media, both as an adsorbed ${ }^{2-6}$ or soluble species. ${ }^{7-9}$ This intermediate could be further reduced to hydrogen peroxide $\left(\mathrm{H}_{2} \mathrm{O}_{2}\right)$ or could break into adsorbed $\mathrm{O}$ and $\mathrm{OH}$ through a chemical step. ${ }^{1,6}$ Depending on the experimental conditions, $\mathrm{H}_{2} \mathrm{O}_{2}$ could be further reduced to water resulting in a complete four-electron pathway or be the final product in a two-electron scheme. In the case of alkaline media, the ORR was proposed to take place through a superoxide $\left(\mathrm{O}_{2}{ }^{-}\right)$intermediate. ${ }^{10,11}$ On the other hand, measurements in neutral solutions pointed out a decrease of $j_{\text {lim }}$ in comparison to the theoretical value as the solution $\mathrm{pH}$ is increased. ${ }^{8}$ Since no hydrogen peroxide is detected in rotating ring-disk experiments under these conditions and measurements show that $\mathrm{H}_{2} \mathrm{O}_{2}$ can be completely reduced at high overpotentials in this $\mathrm{pH}$ range, these results point out that there is a bifurcation point in the ORR mechanism before the formation of $\mathrm{H}_{2} \mathrm{O}_{2}$. It has been proposed that the bifurcation point involves the soluble $\mathrm{OOH}^{\bullet}$ in equilibrium with its adsorbed form. ${ }^{8}$

Regarding the current inhibition observed below $0.3 \mathrm{~V}$ vs. RHE on $\mathrm{Pt}(111)$ in acidic media, it was proposed that it is due to the presence of adsorbed hydrogen which prevents the scission of the O-O bond. ${ }^{12}$ However, recent experiments for the hydrogen peroxide reduction

\footnotetext{
*Electrochemical Society Member.

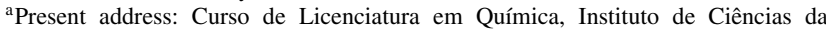

Educação, Universidade Federal do Oeste do Pará, Avenida Marechal Rondon, s/n, CEP 68040-070, Santarém, PA, Brazil.

bPresent address: Department of Physics, Ruhr-University Bochum, 44780 Bochum, Germany.

${ }^{2}$ Present address: Fritz-Haber-Institute der Max-Planck Gesellschaft, 14915 Berlin, Germany.

E-mail: juan.feliu@ua.es
}

reaction (HPRR) in neutral solutions demonstrated that this inhibition is related to the interfacial charge. ${ }^{13}$

All the results mentioned in the previous paragraphs evidence that ORR takes place through a complex set of parallel reactions with a similar rate. Therefore, small changes in the experimental conditions can modify the relative rates of those parallel reactions, resulting in a significant change in the global reaction mechanism.

The modification of the electrode metal surface by different types of adlayers can provide more information about the mechanism of the ORR. ${ }^{14-17}$ One of the most studied cases is the modification of Pt electrodes with bromide adlayers: ${ }^{18-22}$ i) on the one hand, bromide adatoms hinder the adsorption of oxygenated molecules, which are intermediates in the ORR, and therefore displace the onset potential toward more negative values; ii) on the other hand, it has been proposed that bromide adlayers block the pairs of $\mathrm{Pt}$ sites needed for breaking the $\mathrm{O}-\mathrm{O}$ bond, and therefore the reaction proceeds through a two-electron pathway with subsequent $\mathrm{H}_{2} \mathrm{O}_{2}$ formation. ${ }^{19}$ Bromide adlayers have also been used to selectively expose specific sites of a nanoparticle toward the ORR or increasing the ratio of active sites in the catalyst surface. ${ }^{23}$

Bromide adsorption on $\operatorname{Pt}(111)$ has been the object of study in several works using UHV measurements and in-situ electrochemical investigations. ${ }^{24-33}$ The most characteristic feature is the structural transition from a $\mathrm{Pt}(111)-(3 \times 3)-4 \mathrm{Br}$ adlattice at high potentials to a $\mathrm{Pt}(111)-(1 \times 1)$ at low potentials, which is reflected in cyclic voltammetry experiments by a $\mathrm{pH}$-independent sharp peak at $0.185 \mathrm{~V}$ vs. SHE. ${ }^{27,32,34}$ A recent work in phosphate buffer solutions with different $\mathrm{pH}$ shows that the relative strength of bromide adsorption in comparison with $\mathrm{OH}$ adsorption becomes weaker as the $\mathrm{pH}$ is increased and that $\mathrm{pH}$ ca. 9 is the limit value in which bromide can attain sufficient coverage to promote the structural transition. ${ }^{34}$

In this work, further insights into the effect of the presence of adsorbed bromide on $\operatorname{Pt}(111)$ toward the ORR are provided, especially focusing on the solution $\mathrm{pH}$ effect in the inhibition of $j_{\text {lim }}$ caused by the adsorbed layer. In the light of the observed results, some refinements on the effect of $\mathrm{pH}$ on the ORR mechanism are proposed.

\section{Experimental}

Experiments were performed in a glass electrochemical cell with three electrodes following the general procedure described by Korzeniewski et al. ${ }^{35} \mathrm{Pt}(111)$ working electrode was prepared from a 
Table I. Solution compositions for the blank voltammetries in Figure 1.

\begin{tabular}{cl}
$\mathrm{pH}$ & Composition \\
\hline-0.5 & $2 \mathrm{M} \mathrm{HClO}_{4}$ \\
0.1 & $1 \mathrm{M} \mathrm{HClO}_{4}$ \\
1.1 & $0.1 \mathrm{M} \mathrm{HClO}_{4}$ \\
1.5 & $0.032 \mathrm{M} \mathrm{HClO}_{4}+0.068 \mathrm{M} \mathrm{KClO}_{4}$ \\
2.0 & $0.010 \mathrm{M} \mathrm{HClO}_{4}+0.090 \mathrm{M} \mathrm{KClO}$ \\
3.0 & $0.011 \mathrm{M} \mathrm{HClO}_{4}+0.017 \mathrm{M} \mathrm{NaF}+0.082 \mathrm{M} \mathrm{KClO}_{4}$ \\
4.0 & $0.010 \mathrm{M} \mathrm{HClO}_{4}+0.078 \mathrm{M} \mathrm{NaF}+0.022 \mathrm{M} \mathrm{KClO}_{4}$ \\
5.3 & $0.010 \mathrm{M} \mathrm{HClO}_{4}+0.686 \mathrm{M} \mathrm{NaF}$
\end{tabular}

small Pt bead of $2.1 \mathrm{~mm}$ mean diameter according to the procedure described by Clavilier et al. ${ }^{36}$ Before each experiment, the electrode was flame annealed in a propane-oxygen flame, cooled in an $\mathrm{Ar} / \mathrm{H}_{2}$ (3:1) atmosphere and immersed in ultrapure water saturated with these gases to protect the electrode with a water drop. The working electrode was then immediately transferred to the electrochemical cell and contacted with the electrolyte solution under potential control. The initial potential was $0.1 \mathrm{~V}$ for voltammetric characterization without $\mathrm{O}_{2}$ or $1.0 \mathrm{~V}$ in the case of ORR measurements. The reference electrode was a reversible hydrogen electrode (RHE) in all cases except for solutions containing $\mathrm{NaF}$, in which case a $\mathrm{Ag} / \mathrm{AgCl}, \mathrm{KCl}$ (saturated) electrode was used. ${ }^{8}$ In this case, potentials were transformed to the RHE scale after $\mathrm{pH}$ measurement. The counter electrode was a Pt coiled wire cleaned by flame annealing and quenched with ultrapure water before immersion in the cell.
Working solutions were prepared from $\mathrm{HClO}_{4}$ (Merck, for analysis), $\mathrm{KClO}_{4}$ (EMSURE ACS for analysis $99.5 \%-100.5 \%$, Merck), $\mathrm{NaF}$ (Merck, Suprapur, 99.99\%) and KBr (Merck, Suprapur, 99.99\%). Solutions with $\mathrm{pH}$ ranging between 2 and 6 were prepared as in Ref. 8 , ensuring that the solution compositions have high enough buffer capacity for the ORR without appreciable contamination from glass corrosion caused by generated HF (see Table I). Ultrapure water (Elga PureLab Ultra, $18.2 \mathrm{M} \Omega \mathrm{cm}$ ) was employed for glassware cleaning and preparation of all the working solutions. $\mathrm{Ar}, \mathrm{H}_{2}$, and $\mathrm{O}_{2}$ (N50, Air Liquide) were also employed. The working solution was deaerated by bubbling Ar for at least 15 min for experiments in the absence of $\mathrm{O}_{2}$.

The electrode potential was controlled using a waveform generator (PARC 175, EG\&G) together with a potentiostat (eDAQ EA 161) and a digital recorder (eDAQ ED401). ORR experiments were carried out in the hanging meniscus rotating disc electrode configuration (HMRDE) by using an ED101 rotating electrode and a CTV 101 rotation rate controller (Radiometer Analytical). All the experiments were carried out at room temperature.

\section{Results and Discussion}

ORR on $\mathrm{Pt}(111)$ was studied in the presence of different concentrations of bromide ranging from $10^{-4}$ to $10^{-2} \mathrm{M}$ and several $\mathrm{pH}$ values in different solutions prepared with $\mathrm{NaF} / \mathrm{HClO}_{4}$ mixtures. To compare the results for ORR measurements in the absence and presence of specifically adsorbed bromide, this supporting electrolyte was chosen since, unlike bromide, neither fluoride nor perchlorate anions adsorb specifically. ${ }^{8,37}$ To help to understand the effect of the bromide adlayer on the ORR, voltammetric profiles in the absence of $\mathrm{O}_{2}$ were recorded, as shown in Figure 1. In general, the presence

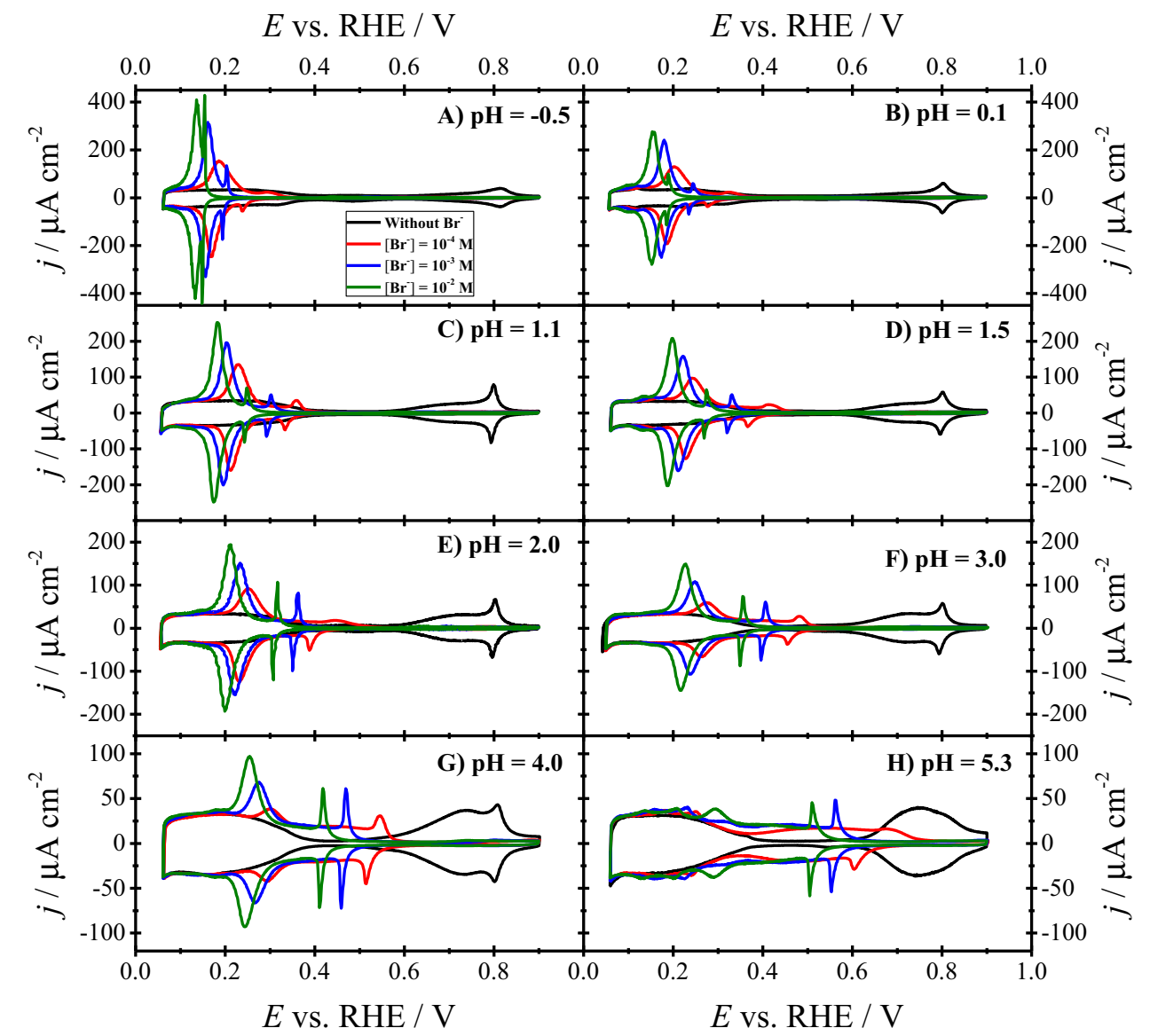

Figure 1. Voltammetric profiles for $\mathrm{Pt}(111)$ in different solutions with $\mathrm{pH}$ values ranging from -0.5 to 5.3 in presence of different concentrations of $\mathrm{KBr}$ from $10^{-4} \mathrm{M}$ to $10^{-2} \mathrm{M}$. Scan rate: $50 \mathrm{mV} \mathrm{s}^{-1}$. 


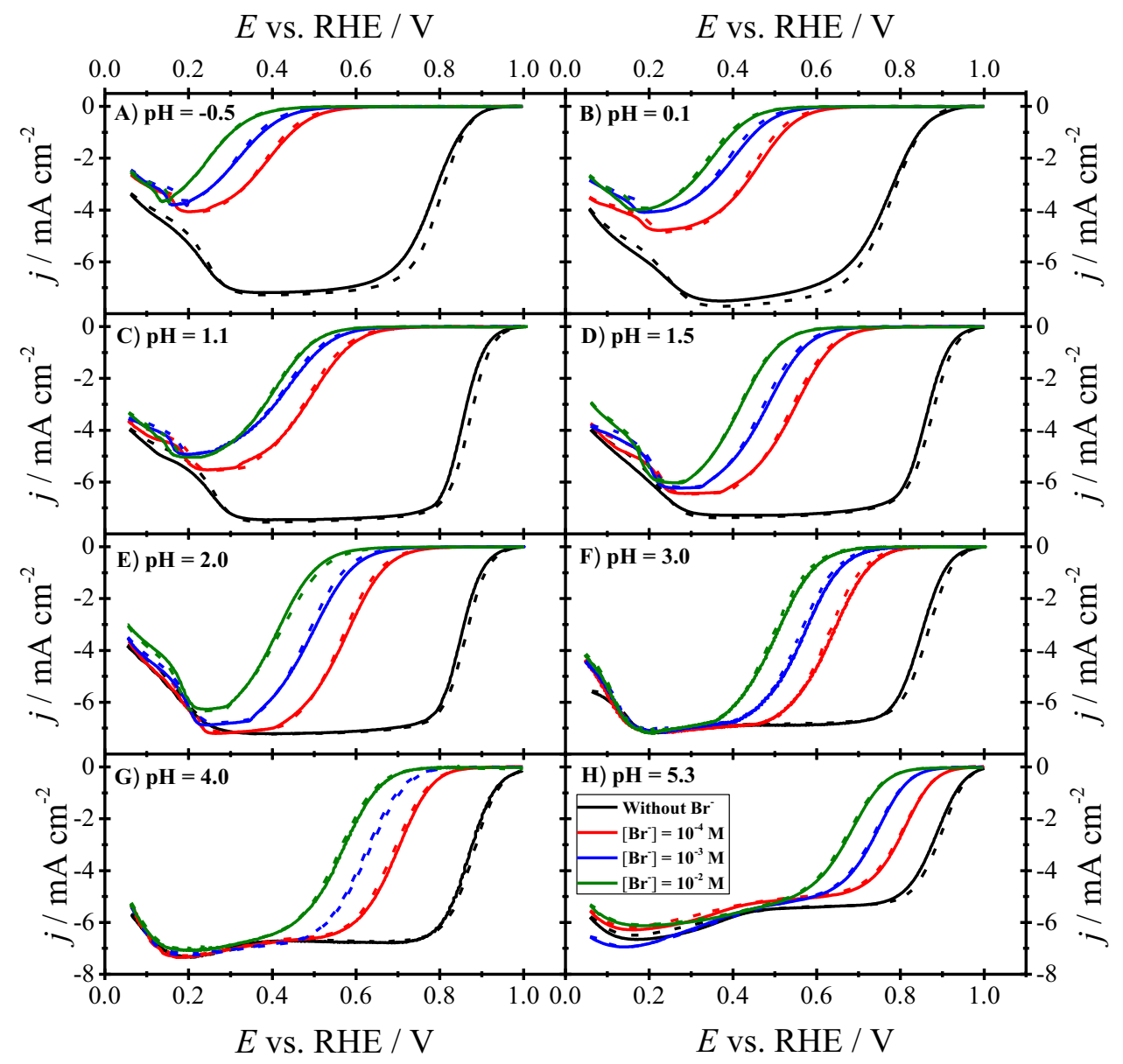

Figure 2. Polarization curves for the ORR on $\mathrm{Pt}(111)$ in different solutions with $\mathrm{pH}$ values ranging from -0.5 to 5.3 in presence of different concentrations of $\mathrm{KBr}$ from $10^{-4} \mathrm{M}$ to $10^{-2} \mathrm{M}$. Solid line: negative-going scan; dashed line: positive-going scan. Scan rate: $50 \mathrm{mV} \mathrm{s}^{-1}$; rotation rate: $2500 \mathrm{rpm}$.

of bromide in the solution implies the disappearance of the $\mathrm{OH}$ adsorption signals characteristic of the voltammogram recorded in the blank electrolyte between 0.6 and $0.8 \mathrm{~V}$. A new signal, linked to the adsorption of bromide on the surface is observed between the hydrogen adsorption states and $1 \mathrm{~V}$, depending on the $\mathrm{pH}$ and bromide concentration in solution (as pointed out in Ref. 34). This new signal shows a spike associated to the transition between a $\operatorname{Pt}(111)-(3 \times$ $3)-4 \mathrm{Br}$ adlattice at positive potentials and a $\operatorname{Pt}(111)-(1 \times 1)$ adlayer at negative potentials. ${ }^{27,32,34}$ It is worth mentioning that for $10^{-4} \mathrm{M}$ $\mathrm{KBr}$ the peaks are less sharp and not symmetrical. This is because the adsorption of bromide for this concentration is still controlled by mass transport and the equilibrium coverage is not reached in the time scale of the $50 \mathrm{mV} \mathrm{s}^{-1}$ sweep. At lower scan rates, the separation between peaks diminishes, as expected (not shown). As the concentration is increased the peaks become sharper and more intense and they shift toward more negative potentials as the formation of a close-packed bromide adlayer becomes thermodynamically more favorable. As can be seen in this figure, bromide adsorption shifts (in the RHE scale) to higher potential values as the $\mathrm{pH}$ increases, but when the profiles are plotted vs. the SHE scale, the spike for the order-disorder transition of the bromide layer appears at constant potential, ${ }^{27,32,34}$ implying that bromide adsorption is a $\mathrm{pH}$-independent process.

Regarding the adsorption strength of bromide, it can be seen that the blank profiles for solutions containing $10^{-2} \mathrm{M} \mathrm{KBr}$ are practically identical to those measured for solutions prepared with phosphate buffers at $\mathrm{pH}$ values $>3 .{ }^{34}$ It can be concluded that bromide adsorption is so strong that the presence of phosphate anions or other species with an adsorption energy lower than that of bromide does not alter its voltammetric behavior. Namely, bromide adsorption can be con- sidered to play a third-body role, preventing the adsorption of any other anion at high potential values, with exception of very strongly adsorbed anions such as $\mathrm{I}^{-}$or $\mathrm{S}^{2-}$. As aforementioned, the adsorption of oxygenated species such as $\mathrm{OH}$ is important for the ORR since they are intermediates in the mechanism. As the $\mathrm{pH}$ increases, $\mathrm{OH}$ adsorption becomes more favorable due to the increase of the concentration of $\mathrm{OH}^{-}$in solution. Being bromide adsorption independent of the $\mathrm{pH}$, the increase in the adsorption strength of $\mathrm{OH}$ with $\mathrm{pH}$ implies that the relative strength of bromide adsorption with respect to $\mathrm{OH}$ must be lower.

ORR measurements in the former conditions are presented in Figure 2. In the case of $0.1 \mathrm{M} \mathrm{HClO}_{4}(\mathrm{pH}=1.1)$, which is the electrolyte most usually reported on the literature, the onset potential in the presence of bromide is significantly displaced to more negative potentials. The higher the concentration of bromide is, the more negative the onset potential is. This could be interpreted assuming that adsorbed bromide inhibits the ORR by blocking the initial adsorption of $\mathrm{O}_{2}$, or its first reduction product, in a stronger way to that described for sulfate or phosphate anions. ${ }^{12,15,19,38}$ The analysis of the evolution of the reaction as a function of $\mathrm{pH}$ and bromide concentration will be carried out using two different parameters: the half-wave potential $\left(E_{1 / 2}\right)$ and the measured $j_{\text {lim }} . E_{1 / 2}$ provides information on the effect of bromide adsorption on the initial stages of the reaction, whereas $j_{\text {lim }}$ indicates the formation of $\mathrm{H}_{2} \mathrm{O}_{2}$ or any other possible soluble intermediates.

When half-wave potentials are analyzed, it can be seen that the presence of bromide implies a shift toward negative values with respect to that obtained in the absence of bromide. This displacement is more important as the $\mathrm{pH}$ diminishes, in parallel with the displacement of 


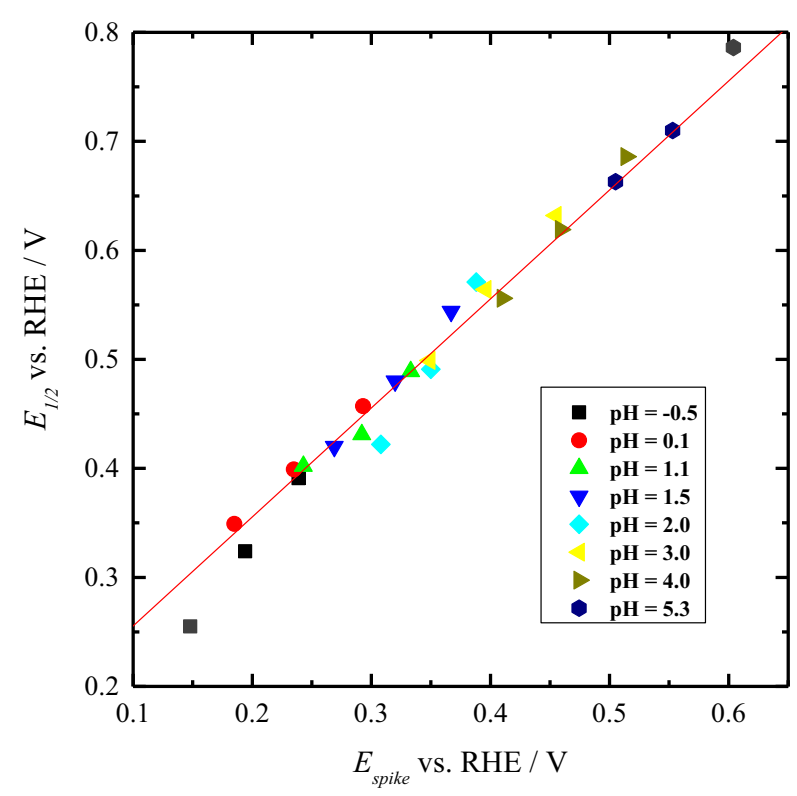

Figure 3. $E_{1 / 2}$ for the ORR from Figure 2 vs. $E_{\text {spike }}$ for the order-disorder transition in the bromide layers from Figure 1 for the different $\mathrm{pH}$ and bromide concentrations. The line represents the fitting to the data using a fixed slope equal to 1 .

the bromide adsorption process to more negative values, as shown in Figure 1. This is because the relative adsorption strength of bromide decreases as the $\mathrm{pH}$ of the solution increases as pointed out in Ref. 33 . To quantitatively analyze this effect, the half-wave potentials for the ORR were plotted versus the potential for the spike $\left(E_{\text {spike }}\right)$ in deaerated solutions, which is the most significant parameter characteristic of the bromine layer. The result is shown in Figure 3. As mentioned above, the voltammetric spike signals the order-disorder phase transition in the adlayer, meaning that at potentials more positive than the spike, bromide forms a compact $(3 \times 3)-4 \mathrm{Br}$ adlattice. As can be seen in Figure 3, a linear relationship between both parameters is found. In fact, the line in this figure represents a linear fitting to all the data with a fixed slope of 1 . The obtained fitting perfectly reproduces the observed behavior and minor deviations are only detected for $\mathrm{pH}=$ -0.5 and $10^{-2} \mathrm{M} \mathrm{KBr}$ and the solution at $\mathrm{pH}=5.3$ with $10^{-4} \mathrm{M} \mathrm{KBr}$. In the first case, the deviation is probably related to the overlapping of the phase transition with the adsorption of hydrogen, whereas in the second case, it is more likely due to the fact that adsorbed $\mathrm{OH}$ plays a role at low bromide concentration and neutral $\mathrm{pH}$. The fitted line has the following equation:

$$
E_{1 / 2}=E_{\text {spike }}+0.156 \mathrm{~V}
$$

This relationship implies that the onset of the ORR is always at potentials more positive than the spike, that is, the onset of the reaction takes place in a situation in which the surface is covered by a compact and ordered layer of bromide and only a very low fraction of $\mathrm{Pt}$ sites is not covered by bromide. This very low fraction of sites has still a large activity because diffusion limiting conditions are already achieved around the potential of the spike.

On the other hand, when the limiting currents in the presence and absence of bromide are compared, the most noticeable feature is the strong diminution of the limiting current densities in the presence of bromide at $\mathrm{pH}<3$. It should be noted that $j_{\text {lim }}$ in the blank electrolyte for $\mathrm{pH} \leq 3$ are constant and equal to the theoretical limiting current for the 4-electron process $\left(7.5 \mathrm{~mA} \mathrm{~cm}^{-2}\right)$. For $\mathrm{pH}$ values between 3 and $12, j_{\text {lim }}$ are smaller, reaching a minimum value for $\mathrm{pH}$ around $6 .^{8}$ The observed diminution at $\mathrm{pH}$ close to neutrality cannot be ascribed to the formation of $\mathrm{H}_{2} \mathrm{O}_{2}$, because this molecule can be effectively reduced on the electrode under this condition. Hence, this diminution has been explained considering the formation of an $\mathrm{OOH}^{\bullet}$ radical. $^{8}$ In $0.1 \mathrm{M}$
Table II. Relative value $(\%)$ of $j_{\text {lim }}$ for the different bromide concentrations at different $\mathrm{pH}$ values with respect to that measured in the absence of bromide.

\begin{tabular}{lcccccccc} 
& \multicolumn{8}{c}{$\mathrm{pH}$} \\
\cline { 2 - 8 }$[\mathrm{KBr}] / \mathrm{M}$ & -0.5 & 0.1 & 1.1 & 1.5 & 2.0 & 3.0 & 4.0 & 5.3 \\
\hline $10^{-4}$ & 56 & 64 & 74 & 88 & 100 & 100 & 100 & 94 \\
$10^{-3}$ & 52 & 54 & 66 & 85 & 97 & 100 & 100 & 100 \\
$10^{-2}$ & 50 & 53 & 66 & 83 & 94 & 100 & 97 & 92
\end{tabular}

$\mathrm{HClO}_{4}$ bromide containing solutions, the diminution in the limiting current at low potentials was proven by Markovic et al. to be related to the shift in the ORR mechanism from 4 to 2 electrons, with the simultaneous detection of $\mathrm{H}_{2} \mathrm{O}_{2}$ in the ring electrode in flow-controlled rotating ring-disc experiments. ${ }^{19}$ In fact, the main motivation of this paper was to study this phenomenon, because it was proposed that strongly adsorbed bromide inhibits the formation of pairs of Pt sites which are necessary for the scission of the O-O bond, which had to take place parallel to the electrode surface, and therefore $\mathrm{H}_{2} \mathrm{O}_{2}$ is obtained as the final product through a two-electron pathway. ${ }^{19}$ In this respect, $j_{\text {lim }}$ in the presence of bromide are slightly higher than half the value obtained in the absence of specific adsorption (see Table II and Ref. 19). Roughly speaking, this means that almost all oxygen molecules would give rise to $\mathrm{H}_{2} \mathrm{O}_{2}$ (as detected on the ring electrode), but a $100 \%$ of selectivity toward $\mathrm{H}_{2} \mathrm{O}_{2}$ is not reached. The same result is obtained in the present work. When the solution $\mathrm{pH}$ is increased, limiting current densities are progressively restored, and at $\mathrm{pH} \geq 3$ the same $j_{l i m}$ is recorded in both the presence and the absence of bromide in solution (Figure 2). In light of these results, measurements were carried out in solutions with high perchloric acid concentrations (Figures 2A and 2B). Interestingly, it can be seen that for the lowest $\mathrm{pH}$ values $(-0.5$ and 0.1$)$ limiting current densities are much closer to totally a half of $j_{\text {lim }}$ in absence of bromide (Table II), suggesting a complete selectivity to the peroxide path in this conditions of high acidity and strong competitive adsorption. In conclusion, a progressive approach to the theoretical $j_{\text {lim }}$ for the four-electron pathway takes place from very low $\mathrm{pH}$ values to higher values, as reported in Table II. In this respect, $\mathrm{pH}=3$ defines the value from which limiting current densities are the same in the presence and in the absence of adsorbed bromide.

Solutions with $\mathrm{pH}=3$ have special properties for Pt electrodes, because around this $\mathrm{pH}$ value the potential of zero total charge ( $p z t c)$ and the potential of zero free charge $(p z f c)$ fall into in the double layer region. For this reason, it was proposed that at $\mathrm{pH}$ around 3 it can be identified with the $\mathrm{pK}_{\mathrm{a}}$ of interfacial water on Pt. ${ }^{39,40}$ Therefore, this could have an influence toward the oxygen reduction since the interaction between the ORR intermediates and the interfacial water layer may be different below and above $\mathrm{pH} 3$. It is important to remark that the $\mathrm{pK}_{\mathrm{a}}$ value for the protonation equilibrium between $\mathrm{O}_{2}{ }^{-}$and $\mathrm{OOH}^{\bullet}$ is $4.8,{ }^{41}$ and that for the adsorbed species at positive potentials could be even lower. ${ }^{42}$ The abundance of one or other species and their possible different reactivity could account for the diminution of the $j_{\text {lim }}$ for the ORR at higher $\mathrm{pH}$ values than $3,{ }^{8}$ and the behavior observed here in the presence of bromide. This could be related with the interfacial $\mathrm{pK}_{\mathrm{a}}$ value for water which is between 3 and $4^{39}$ or with the $\mathrm{pK}_{\mathrm{a}}$ value for $\mathrm{OOH}^{\bullet}$ intermediate. Adžić et al. pointed out that the ordered $\mathrm{Pt}(111)-(3 \times 3)-4 \mathrm{Br}$ structure causes the complete inhibition of the ORR. ${ }^{18,20}$ Therefore, a possible disordering of this structure by $\mathrm{OH}$ adsorption could contribute to restore the limiting current density at $\mathrm{pH}>3$.

To understand these effects and to clarify the observed behavior for the limiting current densities, additional measurements were carried out for the HPRR in the presence of bromide at solutions with $\mathrm{pH}=$ 1.2, 3 and 5.4 (Figure 4). The $\mathrm{H}_{2} \mathrm{O}_{2}$ concentration was selected to have the same value than that corresponding to the saturation concentration of $\mathrm{O}_{2}$ in the same solution. In Figure 4, the solid horizontal gray line stands, in all cases, for the half of the theoretical $j_{\text {lim }}$ for the 


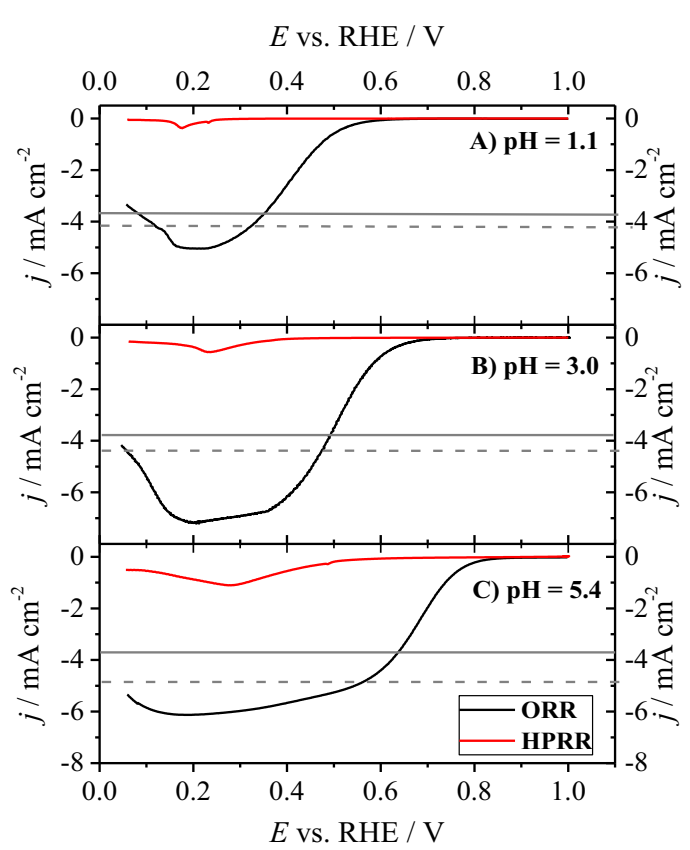

Figure 4. Experimental polarization curves for the ORR (black line) and the HPRR (red line) on $\mathrm{Pt}(111)$ in the presence of $10^{-2} \mathrm{M} \mathrm{KBr}$ in the indicated $\mathrm{pH}$ values. Scan rate: $50 \mathrm{mV} \mathrm{s}^{-1}$. Rotation rate: $2500 \mathrm{rpm}$. Grey solid line represents half $\left(2 \mathrm{e}^{-}\right)$of the theoretical $j_{l i m}$ for the ORR $\left(4 \mathrm{e}^{-}\right)$and the gray dashed line indicates the addition to this value of the experimental $j_{\text {lim }}$ obtained for the HPRR. Measurements with higher upper potential limits were also performed and they pointed out that $\mathrm{H}_{2} \mathrm{O}_{2}$ oxidation is also hindered at high overpotentials.

ORR given by the Levich equation (ca. $3.75 \mathrm{~mA} \mathrm{~cm}^{-2}$ ), assuming a 4-electron process for the ORR. This is the value for $j_{\text {lim }}$ that would be obtained for the ORR with a $100 \%$ selectivity to yield $\mathrm{H}_{2} \mathrm{O}_{2}$ (2electron process) or for the HPRR under diffusion control if $\mathrm{H}_{2} \mathrm{O}_{2}$ had the same diffusion coefficient as $\mathrm{O}_{2}$. As can be seen, only small currents for the HPRR are detected for the solutions under study, being these currents significantly smaller than the theoretical limiting value, implying that the HPRR is hindered but not completely inhibited. Assuming that the ORR takes place in a sequential mechanism in which $\mathrm{H}_{2} \mathrm{O}_{2}$ is formed and then some of the $\mathrm{H}_{2} \mathrm{O}_{2}$ molecules are reduced to water, it would be expected that the limiting current for the ORR would have been equal to that marked by the gray line plus the maximum current measured for the HPRR (the dashed horizontal gray line in Figure 4). However, for the three $\mathrm{pH}$ values studied, $j_{\text {lim }}$ obtained for the ORR is higher than the value given by the dashed line. This difference is more significant for $\mathrm{pH}=3$ since, in the presence of bromide, the HPRR is strongly inhibited while for the ORR the measured $j_{l i m}$ is very near to the theoretical value for a 4electron reaction. This fact suggests that the reduction mechanism is not following a sequential scheme in which hydrogen peroxide is formed as intermediate and there must be a separated path that leads to water formation that does not involve solution $\mathrm{H}_{2} \mathrm{O}_{2}$.

Two main conclusions can be inferred from these results. Primarily, increasing the solution $\mathrm{pH}$ weakens the adsorption of bromide anions with respect to that of $\mathrm{OH}$ and other oxygenated species, and therefore adsorbed intermediates in the ORR reaction are not desorbed favoring the 4-electron pathway, as demonstrated by the high current density values obtained for $\mathrm{pH}=5.4$. Secondly, some other intermediate different from adsorbed $\mathrm{H}_{2} \mathrm{O}_{2}$ should be formed during the ORR, since the current densities recorded are higher than the theoretical values which would be obtained if all the oxygen molecules react to produce $\mathrm{H}_{2} \mathrm{O}_{2}$. This intermediate, which could be probably the proposed hydroperoxyl radical, $\mathrm{OOH}^{\bullet}$, would have a higher adsorption energy than $\mathrm{H}_{2} \mathrm{O}_{2}$ and it could compete to a greater extent

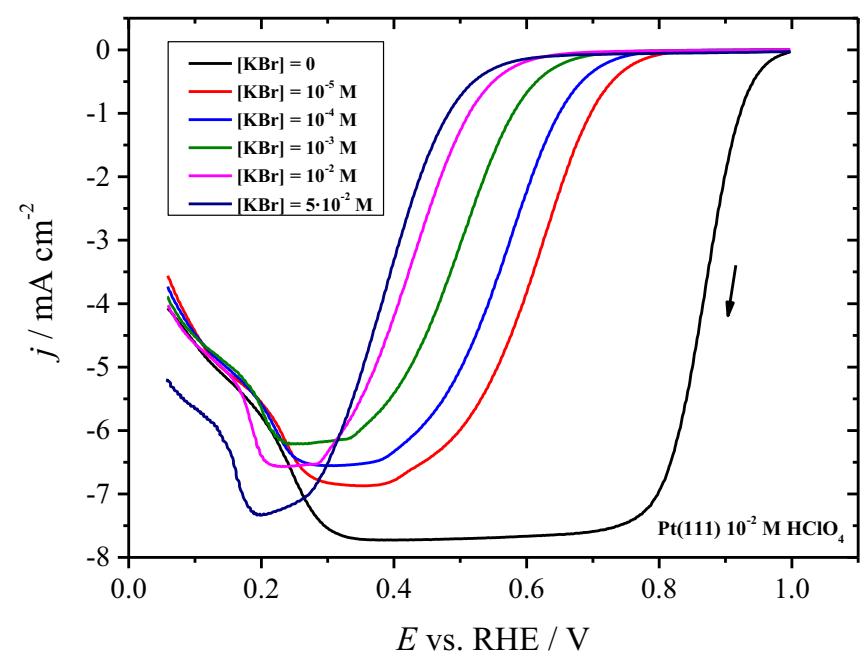

Figure 5. Polarization curves for the ORR on $\mathrm{Pt}(111)$ in $10^{-2} \mathrm{M} \mathrm{HClO}_{4}(\mathrm{pH}$ $=2$ ) and different concentrations of $\mathrm{KBr}$ from 0 to $5 \times 10^{-2} \mathrm{M}$. Scan rate: $50 \mathrm{mV} \mathrm{s}^{-1}$; rotation rate: $2500 \mathrm{rpm}$.

with bromide anions. This is especially evident in the cases of $\mathrm{pH}=3$ and $\mathrm{pH}=5.4$. It has to be taken into account that the same $j_{\text {lim }}$ for the ORR is measured in the absence and in the presence of bromide, while for the HPRR, the diminution in currents is quite important. These results agree with the observations made in a previous work: ${ }^{8}$ while $j_{\text {lim }}$ decreases gradually with $\mathrm{pH}$ for the $\mathrm{ORR}$ at $\mathrm{pH}>3$, this inhibition is not observed for the HPRR. This, together with the results reported in this work in the presence of bromide, strongly suggest that some differences in the ORR and HPRR mechanisms should exist.

One possible explanation for these results is that cations in solution are affecting the reduction mechanism. To gain insight into these effects, preliminary ORR measurements in the initial absence of cationic species in solution (other than protons) and subsequent addition of different amounts of $\mathrm{KBr}$ in $\mathrm{pH}=2$ were carried out (Figure 5). The addition of $\mathrm{KBr}$ to the initial perchloric acid solutions produces the expected behavior: as bromide concentration is increased the onset potential is displaced to more negative values and $j_{\text {lim }}$ progressively decreases. However, for $\mathrm{KBr} \geq 10^{-2} \mathrm{M}$, although the onset potential continues shifting to less positive potentials, $j_{\text {lim }}$ increases when $\mathrm{KBr}$ concentration is increased. These observations indicate that the presence of significant amounts of cationic species may alter the mechanism of the ORR. The presence of $\mathrm{K}^{+}$seems to favor the formation of the intermediate that can compete more effectively with bromide anions, giving rise to higher limiting current densities and decreasing the formation of $\mathrm{H}_{2} \mathrm{O}_{2}$. In fact, if curves from Figure 5 are compared to the cyclic voltammetries in Figure 2 (for which $\mathrm{K}^{+}$concentration is ca. $0.09 \mathrm{M}$ in all cases) with the same bromide concentration, it can be seen that for $10^{-4}$ and $10^{-3} \mathrm{M}, j_{\text {lim }}$ are considerably lower in Figure 5, while for $10^{-2} \mathrm{M}, j_{\text {lim }}$ are almost the same in both cases. Another observation that also supports this hypothesis is that in perchloric acid solution, the current diminishes for $\mathrm{E}<0.3 \mathrm{~V}$ due to the effect of the interfacial charge in the reaction. When the surface charge is negative, $\mathrm{H}_{2} \mathrm{O}_{2}$ reduction is inhibited due to changes in the water structure. ${ }^{13}$ This inhibition in the HPRR is correlated with a diminution in the currents for the ORR in the same region, as can be observed in Figures 2 and 5 for the blank solutions. When the $\mathrm{KBr}$ concentration is $10^{-2} \mathrm{M}$ or higher, there is a significant displacement of the inhibition toward more negative potentials, suggesting an effect of cations in this process. The same experiments were carried out using $\mathrm{NaBr}$ instead of $\mathrm{KBr}$ and the same behavior was observed (not shown).

The addition of $\mathrm{K}^{+}$cations to the blank electrolyte at $\mathrm{pH}=2$ also support the role of cations or its influence on the interfacial water in the ORR mechanism (Figure 6). Moreover, significant differences can 


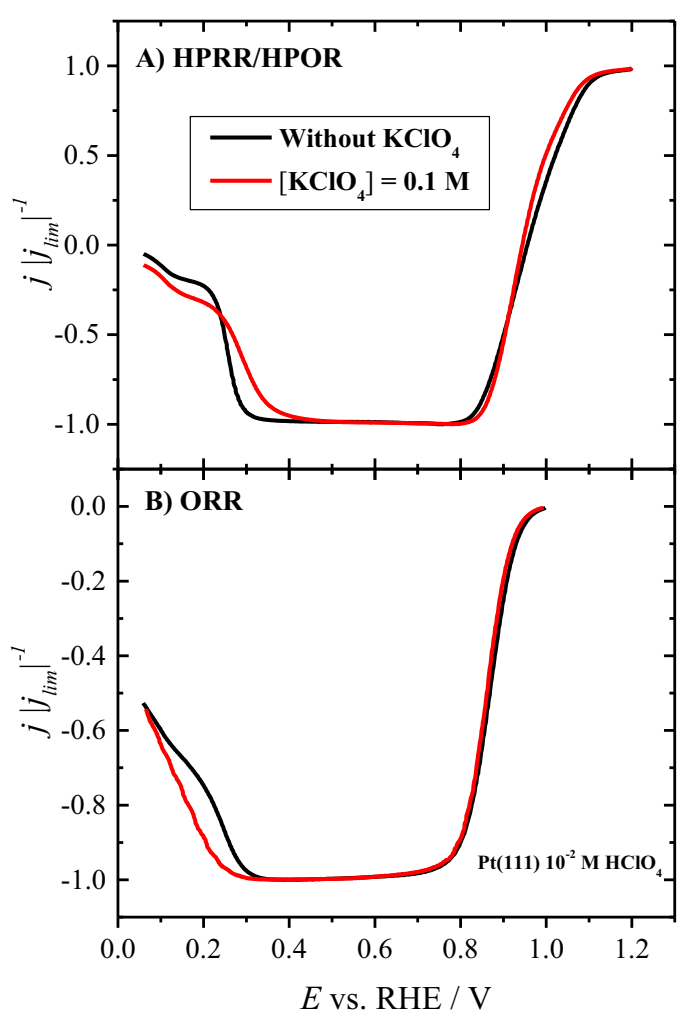

Figure 6. Polarization curves for the HPRR/HPOR (A) and the ORR (B) on $\mathrm{Pt}(111)$ in $10^{-2} \mathrm{M} \mathrm{HClO}_{4}$ in the absence (black line) and in presence of $0.1 \mathrm{M}$ $\mathrm{KClO}_{4}$ (red line). Scan rate: $50 \mathrm{mV} \mathrm{s}{ }^{-1}$; rotation rate: $2500 \mathrm{rpm}$.

be observed for the HPRR and ORR upon the addition of cations. In the case of HPRR, when the cationic species are present the inhibition at potentials below $0.4 \mathrm{~V}$ moves to more positive potential values with respect to that observed in absence of $\mathrm{KClO}_{4}$. These facts indicate that cations play a role in the behavior observed in Ref. 12 . On the other hand, in the case of the ORR in the presence of $0.1 \mathrm{M} \mathrm{KClO}_{4}$ the inhibition at potentials below $0.4 \mathrm{~V}$ appears to be at slightly more negative potentials and, unlike in the absence of cations where two slopes are seen, there is not any change in the slope of the current/potential curve.
The different effect played by the cationic species for both reactions also indicates significant differences in the respective mechanisms, suggesting again that for the ORR a different intermediate is formed. In this discussion, the cationic species effect can also be considered a result of how cation solvation affects water structure, ${ }^{43}$ especially because water is a reaction partner in ORR and HPRR.

These results are in agreement with the conclusions of previous works: ${ }^{8,13}$ while for the HPRR at low potentials shifts to more positive values in the RHE scale as $\mathrm{pH}$ is increased (that is, it is $\mathrm{pH}$-independent in the SHE scale), for the ORR, the potential for the inhibition remains almost unchanged or it even shifts to more negative values. Therefore, some other intermediate different from $\mathrm{H}_{2} \mathrm{O}_{2}$ is likely to be formed during the ORR. Taking into account the available data the mechanism sketched in Figure 7 can be proposed.

The asterisk in the first reaction means that it is affected by bromide adsorption, as discussed in the text. Likely, the formation of $\mathrm{PtOOH}$ can only take place when the adsorption strength of the bromide adlayer weakens.

\section{Conclusions}

In this work, the effect of bromide adlayers on $\mathrm{Pt}(111)$ toward the ORR is thoroughly investigated at different $\mathrm{pH}$ values. The cyclic voltammetric profiles recorded in the absence of oxygen and with different concentrations of bromide are in good agreement with previous results in phosphate buffer solutions, ${ }^{34}$ pointing out that bromide adsorption is strong enough to be independent of the presence of other species with less adsorption energy. The ORR measurements in the presence of bromide anions show that the limiting current densities decrease to nearly half the theoretical value for very acidic $\mathrm{pH}$ values, but as the solution $\mathrm{pH}$ is increased, this difference diminishes and finally vanishes at $\mathrm{pH}=3$. From this $\mathrm{pH}$ value, $j_{\text {lim }}$ in the absence and in the presence of bromide are the same. The onset potential in presence of bromide, however, still shifts to more negative values for solutions with higher $\mathrm{pH}$.

Complementary experiments for the HPRR and with different ionic strength suggest that as the $\mathrm{pH}$ is increased a higher fraction of the ORR intermediates is different from $\mathrm{H}_{2} \mathrm{O}_{2}$, supporting the presence of another intermediate, probably $\mathrm{OOH}^{\bullet}$ species. The adsorption energy of this intermediate would be higher than the adsorption strength of $\mathrm{H}_{2} \mathrm{O}_{2}$. This work has also proven that the concentration of cationic species can also derive the route followed by the ORR.

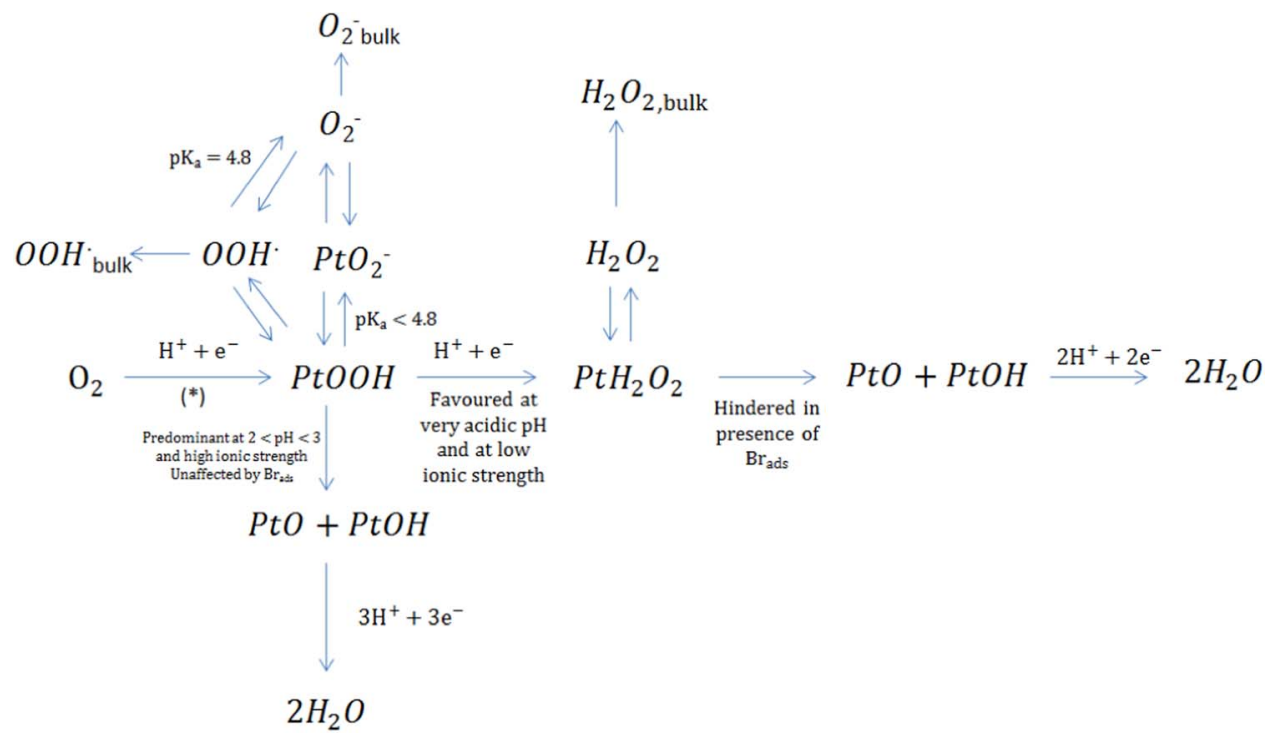

Figure 7. Proposed scheme mechanism for the ORR from the available data. 


\section{Acknowledgments}

This work has been financially supported by the MCINNFEDER (Spain) through project CTQ2016-76221-P. VBM thankfully acknowledges to MINECO the award of a pre-doctoral grant (BES2014-068176, project CTQ2013-44803-P). GABM thanks the postdoctorate fellowship from CNPq (grant no. PDE 233268/2014-6).

\section{ORCID}

Juan M. Feliu (D) https://orcid.org/0000-0003-4751-3279

\section{References}

1. A. M. Gómez-Marín, R. Rizo, and J. M. Feliu, Catal. Sci. Technol., 4, 1685 (2014).

2. J. K. Nørskov, J. Rossmeisl, A. Logadottir, L. Lindqvist, J. R. Kitchin, T. Bligaard, and H. Jónsson, J. Phys. Chem. B, 108, 17886 (2004).

3. R. Jinnouchi, K. Kodama, T. Hatanaka, and Y. Morimoto, Phys. Chem. Chem. Phys., 13, 21070 (2011).

4. H. A. Hansen, V. Viswanathan, and J. K. Nørskov, J. Phys. Chem. C, 118, 6706 (2014).

5. J. Staszak-Jirkovský, E. Ahlberg, I. Panas, and D. J. Schiffrin, Faraday Discuss., 188, 257 (2016).

6. P. S. Ruvinskiy, A. Bonnefont, C. Pham-Huu, and E. R. Savinova, Langmuir, 27, 9018 (2011).

7. A. M. Gomez-Marin and J. M. Feliu, ChemSusChem, 6, 1091 (2013).

8. V. Briega-Martos, E. Herrero, and J. M. Feliu, Electrochim. Acta, 241, 497 (2017).

9. A. M. Gómez-Marín, J. Feliu, and E. Ticianelli, ACS Catal., 8, 7931 (2018).

10. T. J. Schmidt, V. Stamenkovic, P. N. Ross, and N. M. Markovic, Phys. Chem. Chem Phys., 5, 400 (2003).

11. M.-h. Shao, P. Liu, and R. R. Adzic, J. Am. Chem. Soc., 128, 7408 (2006).

12. N. M. Markovic, H. A. Gasteiger, and P. N. Ross, J. Phys. Chem., 99, 3411 (1995).

13. V. Briega-Martos, E. Herrero, and J. M. Feliu, Electrochem. Commun., 85, 32 (2017).

14. Y. B. Mo and D. A. Scherson, J. Electrochem. Soc., 150, (2003).

15. D. Strmcnik, M. Escudero-Escribano, K. Kodama, V. R. Stamenkovic, A. Cuesta, and N. M. Marković, Nat. Chem., 2, 880 (2010).

16. I. Oh, M. E. Biggin, and A. A. Gewirth, Langmuir, 16, 1397 (2000).

17. X. Li and A. A. Gewirth, J. Am. Chem. Soc., 127, 5252 (2005).

18. J. X. Wang, N. S. Marinković, and R. R. Adžić, Colloids Surf., A, 134, 165 (1998).

19. N. M. Markovic, H. A. Gasteiger, B. N. Grgur, and P. N. Ross, J. Electroanal. Chem., 467, 157 (1999).
20. R. R. Adžić and J. X. Wang, Electrochim. Acta, 45, 4203 (2000).

21. I. Katsounaros, W. B. Schneider, J. C. Meier, U. Benedikt, P. U. Biedermann, A. Cuesta, A. A. Auer, and K. J. J. Mayrhofer, Phys. Chem. Chem. Phys., 15, 8058 (2013).

22. A. J. J. Jebaraj, N. S. Georgescu, and D. A. Scherson, J. Phys. Chem. C, 120, 16090 (2016).

23. Y. Cai, C. Ma, Y. Zhu, J. X. Wang, and R. R. Adzic, Langmuir, 27, 8540 (2011).

24. J. M. Orts, R. Gómez, J. M. Feliu, A. Aldaz, and J. Clavilier, J. Phys. Chem., 100, 2334 (1996).

25. G. A. Garwood Jr. and A. T. Hubbard, Surf. Sci., 112, 281 (1981).

26. J. L. Stickney, S. D. Rosasco, G. N. Salaita, and A. T. Hubbard, Langmuir, 1, 66 (1985).

27. G. N. Salaita, D. A. Stern, F. Lu, H. Baltruschat, B. C. Schardt, J. L. Stickney, M. P. Soriaga, D. G. Frank, and A. T. Hubbard, Langmuir, 2, 828 (1986).

28. C. A. Lucas, N. M. Markovic, and P. N. Ross, Surf. Sci., 340, L949 (1995).

29. H. A. Gasteiger, N. M. Markovic, and P. N. Ross, Langmuir, 12, 1414 (1996).

30. J. M. Orts, R. Gómez, J. M. Feliu, A. Aldaz, and J. Clavilier, Langmuir, 13, 3016 (1997).

31. N. Garcia-Araez, V. Climent, E. Herrero, J. Feliu, and J. Lipkowski, J. Electroanal. Chem., 591, 149 (2006).

32. S. Tanaka, S. L. Yau, and K. Itaya, J. Electroanal. Chem., 396, 125 (1995).

33. E. Bertel, K. Schwaha, and F. P. Netzer, Surf. Sci., 83, 439 (1979).

34. G. A. B. Mello, V. Briega-Martos, V. Climent, and J. M. Feliu, J. Phys. Chem. C, 122, 18562 (2018).

35. C. Korzeniewski, V. Climent, and J. M. Feliu, in Electroanalytical Chemistry: A Series of Advances, A. J. Bard and C. Zoski, eds., Vol. 24, p. 75, CRC Press, Boca Raton, (2012).

36. J. Clavilier, D. Armand, S. G. Sun, and M. Petit, J. Electroanal. Chem., 205, 267 (1986).

37. R. Martínez-Hincapié, P. Sebastián-Pascual, V. Climent, and J. M. Feliu, Electrochem. Commun., 58, 62 (2015).

38. A. Kuzume, E. Herrero, and J. M. Feliu, J. Electroanal. Chem., 599, 333 (2007).

39. R. Rizo, E. Sitta, E. Herrero, V. Climent, and J. M. Feliu, Electrochim. Acta, 162 138 (2015).

40. R. Martinez-Hincapie, P. Sebastian-Pascual, V. Climent, and J. M. Feliu, Russ. J. Electrochem., 53, 227 (2017).

41. D. Behar, G. Czapski, J. Rabani, L. M. Dorfman, and H. A. Schwarz, J. Phys. Chem., 74, 3209 (1970).

42. R. Martinez-Hincapie, A. Berna, A. Rodes, V. Climent, and J. M. Feliu, J. Phys Chem. C, 120, (2016).

43. A. Berna, V. Climent, and J. M. Feliu, Electrochem. Commun., 9, (2007). 